\title{
A SEGURIDADE SOCIAL EM PAUTA: A LUTA POLÍTICA DOS/AS IDOSOS/AS ${ }^{1}$
}

\author{
Eulália Lima Azevedo
}

\begin{abstract}
RESUMO
Neste artigo proponho pensar os/as idosos/as na condição de atores políticos que, pela ação direta, movimentam-se e impõem-se como sujeitos capazes de intervir nos espaços públicos de decisão e modificar os padrões culturais vigentes relacionados à forma de viver dos que envelhecem. Busco ilustrar esta análise com a da criação do Fórum Permanente em Defesa do Idoso no estado da Bahia. Este apresenta-se como uma nova estratégia para ampliar a base de sustentação do movimento dos/as aposentados/as e pensionistas que, em várias manifestações nas ruas e praças públicas de Salvador, sempre pautam, em seus discursos, a defesa dos direitos de todos/as os/as idosos/as, bem como a defesa da Seguridade Social Pública, especificamente contra as reformas da Previdência, consideradas de cunho privatista.
\end{abstract}

Palavras - Chave: Velhice. Proteção social. Direitos. Gênero.

\footnotetext{
${ }^{1}$ Este artigo é uma versão modificada de um dos capítulos da tese de doutoramento "Um palco de múltiplas vozes: nova invenção dos/as idoso/as em luta pela cidadania", apresentada ao Programa de PósGraduação em Ciências Sociais da Universidade Federal da Bahia (UFBA) e defendida em março de 2010 (AZEVED0, 2010).

${ }^{2}$ Professora na Universidade Salvador - Laureate International Universities/UNIFACS. Pesquisadora associada do Núcleo de Estudos Interdisciplinares sobre a Mulher - NEIM/ UFBA. Brasil. eulaliaazevedo@uol.com.br
} 


\title{
SOCIAL SECURITY ON THE AGENDA: THE POLITICAL STRUGGLE OF THE AGED
}

\begin{abstract}
In this article I propose thinking of the elderly in the condition of political actors who, by direct action, move around and impose themselves as subjects capable of intervening in public decision-making and modify existing cultural patterns related to the way of life of those who age. I seek to illustrate this analysis with the one of the creation of the Permanent Forum in Defense of the Elderly in the state of Bahia. This presents itself as a new strategy to broaden the support base of the movement of the retirees and pensioners who, in various manifestations in the streets and public squares of Salvador, always focused their speeches on the defense the rights of all elderly as well as the defense of Public Social Security, specifically against the reforms of Social Security, considered of privatizing nature.
\end{abstract}

Keywords: Old age. Social protection. Rights. Gender.

\section{INTRODUÇÃO}

história das políticas governamentais de proteção social no Brasil traz a marca do
peso relativo das categorias profissionais no processo de produção, mas, sobretudo,
na força da sua organização para desenvolver a luta política. Assim, a primeira Aposentadoria e Pensão (CAP), instituída em 24 de janeiro de 1923, deveu-se à força reivindicativa de trabalhadores que ocupavam posição estratégica na economia agroexportadora de então - os ferroviários. Nesse sentido, os trabalhadores dessa categoria foram os pioneiros no usufruto de cobertura previdenciária, no Brasil, quando desligados da produção por velhice, invalidez ou tempo de serviço, seguidos, em 1926, pelos estivadores e marítimos. 0 sistema de Caixas de Aposentadorias e Pensões (CAPs) foise ampliando em obediência à ordem de combatividade das categorias profissionais. Desse modo, a fragmentação e dispersão das trabalhadoras domésticas e dos autônomos explicam o atraso na definição de políticas destinadas à inclusão desses segmentos no sistema previdenciário. Do mesmo modo, somente a quebra do conformismo dos/as trabalhadores/as rurais, com a emergência das mobilizações das Ligas Camponesas, na segunda metade da década de 1950, veio garantir a atenção do poder público sobre esses/as trabalhadores/as e a sua incorporação na política de proteção social nacional.

Sustentados nesses saberes adquiridos na luta pela ampliação dos direitos previdenciários constantes das pautas de reivindicações nas negociações sindicais no período pré-64, ora na condição de dirigentes sindicais, ora na de militantes de base ou simplesmente membros de determinados ramos de atividade, a partir de 1980 a geração 
de aposentados/as e pensionistas estudada neste trabalho organizou, em todo o país, uma estrutura própria de ação reivindicativa. Esses/as velhos/as trabalhadores/as, hoje aposentados/as, foram membros ativos nos Institutos de Aposentadorias e Pensões (IAPs), estrutura previdenciária de então, fragmentada por categoria profissional. Muito do poder político dos líderes sindicais desse período advinha dessa participação na estrutura desses Institutos, com a qual articulavam as demais questões trabalhistas tratadas no Ministério do Trabalho e Previdência Social. Assim, os líderes sindicalistas assumiam a luta pelos direitos previdenciários que se dava no seio do movimento sindical (AZEVED0, 2005; SIMÕES, 2000a).

A administração dos IAPs sob o controle do Estado, que se abstinha de participar da gestão das CAPs, mas condicionava a escolha e nomeação dos presidentes dos Institutos de Aposentadorias ao referendo do Ministério do Trabalho, Indústria e Comércio (MTIC), criado em 1930, caracteriza uma das grandes diferenças entre esses dois momentos da proteção previdenciária no Brasil. Nessa fase, o sistema previdenciário comportava outras diferenciações quanto à qualidade e volume dos benefícios e serviços prestados, na medida em que as categorias profissionais de maior importância econômica, que agregavam, em função disso, maior poder político e organizativo, dispunham de maior volume de recursos que as demais, acabando por reforçar as desigualdades entre as diversas categorias profissionais. Nesse sentido, devido ao entrelaçamento da legislação trabalhista, sindical e previdenciária, uma melhor cobertura dos benefícios e serviços da previdência e vice-versa estava diretamente relacionada a uma maior atuação dos sindicatos, constituindo a previdência social num forte elemento de mobilização política.

Intensos debates se fizeram sobre as questões previdenciárias, no bojo das mobilizações dos trabalhadores/as a partir da segunda metade da década de 1940, à luz de vários projetos que visavam unificar o sistema. A concretização efetiva da proposta polêmica e contraditória de unificação do sistema previdenciário brasileiro, que permeou toda sua história, só ocorreu no regime militar, por meio do Decreto-Lei $\mathrm{n}^{0}$ 72/66, que criou o Instituto Nacional de Previdência Social (INPS). Este passou a filiar todos os/as trabalhadores/as urbanos, independentemente das suas categorias profissionais, com exceção dos servidores públicos civis da União, atendidos pelo Instituto de Pensões e Aposentadoria dos Servidores do Estado (IPASE). Nessa conjuntura, os tecnocratas foram mobilizados e assumiram todos os níveis de decisão do sistema previdenciário brasileiro. Várias modificações ocorreram nesse período, valendo destacar a criação, em 1971, do Programa de Assistência ao Trabalhador Rural (Prorural). Pela Lei $\mathrm{n}^{0}$ 5.859, de 11 de dezembro de 1972, foi estendido aos trabalhadores/as domésticos/as a cobertura previdenciária, bem como aos/às trabalhadores/as autônomos/as em 1973 (AZEVEDO, 2005; HADDAD, 1991; SANTOS, 1979). 


\section{A LUTA POLÍTICA NA AGENDA DA VELHICE}

Com a unificação do sistema previdenciário brasileiro e a emergência do "novo sindicalismo", que assumiu a hegemonia do movimento sindical a partir da década de 1970, os aposentados/as e pensionistas viram-se na condição de abandono político, visto que suas demandas deixaram de ser pautadas pelas lutas dos jovens trabalhadores/as. 0 babitus, nos termos de Bourdieu (2003), apresenta-se como um referencial explicativo dessa questão bastante útil, como já tivemos oportunidade de discutir (AZEVEDO, 2005). Os protagonistas do campo sindical têm aí seu habitus estruturado por meio de relações que se dão em seu interior; como em qualquer campo, as posições sociais são demarcadas conforme a correlação de forças em permanente tensão inerente às relações de poder. A ordem do lugar ocupado pelos agentes individualmente ou por um grupo de agentes é definida pela valoração social do capital simbólico de cada um (BOURDIEU, 2003).

No referido campo sindical, as tensões entre seus protagonistas deixam como saldo reduzidos recursos de poder aos aposentados/as e pensionistas, considerando 0 desvalor de seu capital simbólico, vez que a aposentadoria é vista como um rito de passagem para a velhice (HAREVEN, 1999) e esta foi quase sempre representada como um momento de incapacidade, decadência da existência humana e ausência de perspectiva de futuro. Esta é a marca da ideologia da velhice, especialmente numa sociedade pautada em valores sociopolíticos de acumulação de riqueza. Dado que, de modo geral, os velhos/as não participam mais do processo produtivo, até porque não lhes oportunizam isso, eles perdem, por consequência, não só seu lugar social, mas também seu valor simbólico (BIRMAN, 1995), num mundo encantado com 0 paradigma da eterna juventude, haja vista a grande corrida aos recursos da tecnologia da juvenilização, não importando os custos, perdas e danos nela implicados.

Para responder à negligência dos jovens sindicalistas quanto às suas demandas, os aposentados/as não se deram por rogados e se organizaram em Associações, Federações por Estado e uma Confederação em âmbito nacional, a Confederação Brasileira de Aposentados e Pensionistas (Cobap). Armados com esses instrumentos organizativos jogaram-se em campo, assumindo, como sujeito social, a defesa de seus direitos. $^{3} \quad$ Num processo perpassado por tensões, divergências, rivalidades, competitividades, negociações e alianças, foram delineando sua identidade coletiva, ancorada na definição jurídico-legal de quem compunha a categoria de aposentados/as e pensionistas. Esse dado objetivo possibilitou aos velhos/as trabalhadores/as imaginarem uma "comunidade" de milhões de brasileiros/as cunhada na expressão “[...] somos a maior categoria deste País.” (SIMÕES, 2000a, p. 163), que fazia jus à

\footnotetext{
${ }^{3}$ Sobre a estrutura do sistema previdenciário no Brasil e o movimento dos aposentados, ver Azevedo (2005); Hadad (1991) e Simões (2000a, 2000b).
} 
aposentadoria por longos anos de trabalho, produzindo riquezas para toda a Nação e contribuindo para o sistema previdenciário. Entretanto, o contrato que sustentava tal acordo dava sinais de ruptura, considerando os baixos valores dos benefícios, as dificuldades na concessão dos direitos, as filas torturantes nos postos do INSS e assim por diante, situação que permanece cada vez mais crítica.

Na primeira fase da mobilização reivindicativa dos aposentados, muitas das suas associações (em número ainda reduzido em seu total) não gozavam de autonomia, visto que se subordinavam politicamente aos sindicatos das suas respectivas categorias, que lhes cediam espaço em suas sedes para seu funcionamento e, não raro, apoio financeiro, na medida em que seus associados, ainda um pequeno contingente, não ofereciam condições de fazer frente aos custos das mobilizações. ${ }^{4}$ Naquele momento, eles priorizavam a luta judicial, ajuizando processos contra a Previdência Social, buscando corrigir as perdas nos valores de seus benefícios acumuladas ao longo do tempo, desde 0 final da década de 1970, em função de falhas no cálculo do reajuste dos benefícios de aposentadoria, ao tempo em que atuavam junto aos parlamentares no Congresso Nacional.

Sob a influência do ideário dos movimentos sociais no cenário da abertura política do pós-70, as frequentes vitórias alcançadas no campo jurídico se transformaram num recurso estratégico para aumentar a receita das associações, para atrair os associados, e propiciar maior visibilidade da ação coletiva dos aposentados (SIMÕES, 2000a) que, movidos pelo entusiasmo, acorriam às Associações e Federações em cada estado. É nesse momento que, segundo o mesmo autor, expressa-se um programa de atuação próprio de um grupo de interesse, na medida em que destacam reivindicações específicas de um determinado grupo e realizam ações focadas na articulação parlamentar e na luta judicial.

Com a estrutura organizacional que se estendia por todo o território nacional, a ação coletiva dos aposentados/as e pensionistas foi conquistando cada vez mais autonomia em relação aos sindicatos. Assumindo voz própria, chegavam a Brasília caravanas de idosos/as beneficiários de aposentadorias e pensões, sob a coordenação da Cobap, e frente a frente com os agentes públicos, protestavam contra a política de previdência que atentava contra a dignidade dos que envelheceram trabalhando e contribuindo para o desenvolvimento do país e do sistema previdenciário. Nesse processo, esses idosos/as foram promovendo mobilizações sempre mais expressivas e ganhando espaço na mídia. 0 maior destaque nesse período fica por conta da grande atuação no Congresso Constituinte, para defender suas reivindicações sem temer 0

\footnotetext{
${ }^{4}$ Ainda hoje persiste essa realidade, embora em pequeno número e sob o foco da crítica das associações autônomas.
} 
desconforto das péssimas condições de alojamento enfrentadas na capital política do país.

Um padrão de mobilização, revelado por dupla face, ora como grupo de interesse, ora como um grupo de protesto coletivo organizado, característico de outras formas de ação coletiva, descortina-se aos olhos do analista. Essas mobilizações tiveram como resposta grandes avanços no corpo da Constituição de 1988 (BRASIL, 2000), que instituiu a garantia de direitos constantes da maioria das reivindicações dos aposentados/as e pensionistas. Trouxe ainda, pela primeira vez, o conceito de seguridade social como orientação do sistema de proteção social brasileiro, ancorado em três pilares das políticas públicas: Saúde, Assistência e Previdência. As vitórias assim conquistadas trouxeram mais munição à disposição dos idosos/as. Num crescendo, suas lutas iniciadas nos anos 1980 passaram pelo Congresso Constituinte e extrapolaram suas fronteiras para fazer cumprir as conquistas inscritas na Constituição. Tais lutas atingiram seu ápice nos primeiros anos da década de 1990, culminando com a histórica mobilização pelos 147\%, até agora só discutida nos trabalhos de Azevedo (2005), Hadad (1991) e Simões (2000b). A mobilização pelos 147\% se constituiu na luta pela correção do valor dos proventos dos aposentados/as e pensionistas pelo mesmo índice de correção do salário mínimo. Naquela ocasião, a Portaria $\mathrm{n}^{0}$. 485 concedeu reajustes diferenciados aos aposentados/as e pensionistas. Para aqueles/as que ganhavam até um salário mínimo, o reajuste foi de $147,06 \%$. Aos demais, que ganhavam acima de um salário mínimo, o reajuste dos benefícios foi de 54,6\%, de acordo com o artigo 146 das Disposições Transitórias da Lei no 8.213, de 24 de julho de 1991, que instituíra o Plano de Benefícios da Previdência (AZEVEDO, 2005; HADDAD, 1991; SIMÕES, 1997, 2000a).

0 que merece ser destacado com referência àquele fenômeno é que, com ele, culminou o desvelar da ação coletiva dos aposentados para além dos limites restritos de um grupo de interesse circunscrito ao âmbito de vantagens específicas de um setor social. Os aposentados/as, nesse processo de afirmação de sua identidade coletiva, acreditando no "somos a maior categoria deste país", interpelaram a sociedade, todos os trabalhadores/as da ativa, os sindicalistas, os jovens e mobilizaram a opinião pública em geral em favor da Previdência Social Pública, entendida como uma instituição que, nos termos de Cabral (2002, p. 65), “[...] influencia no ordenamento da sociedade brasileira” principalmente porque "[...] ela está associada à história de milhões de brasileiros de gerações passadas e presentes, que contribuíram para construí-la e dela dependem para assegurar ou completar meios de sobrevivência”. Desse modo, ela é pensada com referência não só a seus beneficiários, mas como um direito de cidadania que diz respeito a toda a sociedade (SIMÕES, 2000a).

0 caráter privatizante embutido nas propostas de reforma do sistema previdenciário, apresentadas e aprovadas, em um primeiro momento, no governo Fernando Henrique Cardoso e, num segundo, no governo Luis Inácio Lula da Silva, tem 
sido veementemente denunciado pelos velhos/as trabalhadores/as como um atentado à solidariedade entre as gerações, princípio moral que sustenta, desde o final do século XIX, os primeiros contratos sociais de proteção social pública. A ruptura desse princípio, de acordo com os próprios discursos dos/as aposentados/as militantes, trazia e traz incertezas para aqueles/as que já se aposentaram, mas as gerações jovens e a sociedade figuram como os maiores perdedores, visto que é o futuro do direito a se aposentar um dia que aparece ameaçado. Nesse sentido, percebemos, como Simões (2000a), que a ação coletiva dos/as aposentados/as vem legitimando suas reivindicações, na medida em que a aposentadoria pela qual eles lutavam e ainda continuam defendendo passou a ser representada como um direito universal.

Ficou patente o caráter universal conferido à política previdenciária que acabava de se constituir em um dos pilares da seguridade social ao lado das políticas de saúde e assistência social, das quais nenhum/a cidadão e cidadã pode prescindir, mormente com 0 avançar da idade. Além disso, uma proposta de mudança cultural orientadora da ação coletiva dos aposentados/as se configura, quando, corajosamente, em ruidosas manifestações públicas pelas ruas e praças do país inteiro, surpreendendo os agentes do Estado e toda a sociedade brasileira, desmontaram os pressupostos da ideologia da velhice, cujo suporte está fincado na imagem de todo aposentado como aquele velho dependente, que não tem mais controle sobre seu corpo e suas emoções, com suas habilidades mentais e intelectuais comprometidas, incapaz, portanto, de assumir decisões sobre sua vida. Ademais, imbuídos do espírito de seguridade social e de "reinvenção da velhice" (DEBERT, 1999) os/as velhos/as trabalhadores/as em movimento, ao lado de outros agentes sociais, pensaram e apresentaram novas regras, tanto do ponto de vista do sistema organizativo quanto do sistema político da sociedade, enfeixadas na proposta de um corpus normativo de garantia de direitos daqueles/as que continuam vivendo além dos sessenta anos de idade. Após mais de dez anos de efetivas lutas, discussões e modificações, tal proposta foi aprovada no Congresso Nacional na forma da Lei $n^{0} 10.741$ (BRASIL, 2007) que instituiu o Estatuto do Idoso no dia 3 de outubro de 2003.

A expressão da capacidade de luta desses idosos/as demonstra o quão justa é sua demanda por uma nova representação do aposentado e da velhice, ancorada em seu reconhecimento enquanto sujeito de seu modo de existência, capazes de defender seus interesses por si próprios. Essa constatação mudou a postura da sociedade, que passou a entender que a defesa de suas demandas significa menos comiseração do que apoio aos cidadãos de pleno direito, aposentados/as, pensionistas e todos/as aqueles/as que trabalham, ou ainda virão a trabalhar ou nunca participaram das relações trabalhistas. No entanto, os dois sentimentos se entrecruzam, especialmente pela forma como a mídia apresenta sua cobertura à ação coletiva dos aposentados/as. 
A análise da participação dos aposentados/as e pensionistas como sujeito social nos processos políticos, como apresentado, permite-nos categorizar tal ação coletiva para além do âmbito restrito de um grupo de interesse, ou grupo de pressão política, na medida em que não se ateve apenas às reivindicações por melhorias dos valores dos benefícios de um setor social específico da sociedade. Ao contrário, no processo de suas mobilizações, as pessoas de mais idade, ao afirmarem a imagem do aposentado ativo, reivindicaram-se portadores dos atributos básicos ao homem e à mulher para lograrem o status de cidadãos plenos e confiáveis. Assim, questionaram a imagem tradicional da velhice, inserindo-a em outra dimensão cujos valores se opunham àqueles comumente aceitos; contribuíram, desse modo, para a construção de representações novas e positivas sobre esta etapa da vida, cuja experiência todos/as viverão. Basta não morrer na juventude. Ademais, nos constantes apelos aos/às trabalhadores/as da ativa, aos/às jovens, aos/às demais idosos/as e à sociedade em geral, tomaram a defesa da aposentadoria num sentido muito além de seus interesses particulares e de grupo imediato, colocando-a como direito universal de cidadania na perspectiva de seguridade social. Na Bahia, por meio do Fórum Permanente em Defesa do Idoso, o movimento põe raízes para além dos limites do direito à aposentadoria, para a defesa dos direitos à vida digna para todos/as que transpõem, no tempo, o marco dos 60 anos, como direito universal.

Criado em 27 de janeiro de 2004 esse Fórum surge para articular outras entidades e grupos que trabalham e lidam com idosos/as e a problemática do envelhecimento, com destaque para os grupos nos quais as mulheres idosas figuram em maioria, os grupos de convivência de idosas/os e os grupos de "terceira idade", tendo como principal orientação a implementação do Estatuto do Idoso. A criação desse Fórum $^{6}$ se impõe ao movimento dos aposentados/as, pensionistas e idosos/as, na Bahia, como estratégia política para (re)afirmar sua condição de sujeito social de defesa dos diretos da pessoa idosa, ampliando sua base de sustentação. Essa necessidade surge para contrapor a tentativa dos jovens sindicalistas de se apresentarem como interlocutores dessa geração mais velha junto aos agentes públicos, por meio de organismos vinculados aos sindicatos das respectivas categorias profissionais e às centrais sindicais, como já tive oportunidade de discutir em outros trabalhos (AZEVED0, 2005, 2010). Os/as velhos/as em movimento buscaram, mediante uma nova pedagogia, alcançar os Grupos de Convivência e de "terceira idade" constituídos basicamente por mulheres idosas que guardam em sua trajetória de vida os constrangimentos de gênero, de modo

\footnotetext{
5 As aspas no termo "terceira idade" implicam assumir aqui uma posição crítica diante dessa nova invenção da sociedade capitalista que, no rol das classificações por idade, encontra uma forma de negar a velhice para constituir um novo cenário de gestão do envelhecimento, na busca, sobretudo, de um filão mercadológico promissor (MOTTA, 2000; DEBERT, 1999).

${ }^{6}$ Sempre que o termo Fórum for utilizado estará referido ao Fórum Permanente em Defesa do Idoso.
} 
que, para a maioria delas, a participação política no espaço público é algo absolutamente novo.

\section{DESENHANDO E COLORINDO UM NOVO CAMINHO}

0 estudo comparativo de condições concretas e representações que estruturam 0 cotidiano dos/as agentes dos diferenciados grupos de idosos/as pesquisados/as se impôs neste estudo. Considero-as como elemento-chave para a análise do alcance da pedagogia que o movimento político dos/as aposentados/as e pensionistas vem elaborando, no que se relaciona à prática cotidiana e à subjetividade das pessoas que se encontram nos grupos de idosos/as, com destaque especial para aqueles/as dos grupos de convivência, mulheres idosas em sua grande maioria. Essa dinâmica confirma, ainda, muito da complexidade das situações vividas pela população que protagoniza o fenômeno mundial de maior longevidade da história, contribuindo para evitar generalizações de situações singulares.

A geração das mulheres que experimenta a fruição da conquista social do fenômeno da maior longevidade viveu e vive mais fortemente os constrangimentos que as construções sociais ancoradas no gênero impunham. Por tais condicionantes foram se sedimentando em sua consciência as marcas de uma trajetória vivida à margem dos espaços nos quais se pensa e define a organização da sociedade, isto é, espaços em que se exercita o poder.

Considerar a força dos aspectos ideológicos torna compreensível a forma submissa como muitas mulheres idosas vêm participando das atividades que se destinam a melhorar sua condição de vida e a de todos os que envelhecem. Tais aspectos se conjugaram ao longo da história para impor a identificação das mulheres às experiências da esfera privada da família. Assim, foi fomentado o reforço da ideia de sua inadequação inata aos requerimentos do mundo público/político, mergulhado no fluxo das disputas de ideias embasadas em interesses divergentes, que buscam garantir decisões que mais lhes favoreçam. Esses constrangimentos se complexificam na velhice, visto que a desautorização devida ao gênero se conjuga àquela devida à idade avançada, expressão das relações entre as gerações, formatadas, não raro, sob a base de conflitos inerentes às disputas de poder.

Tomo por base todos esses elementos teóricos para pensar similaridades e diferenças que fundamentam as condições, tanto simbólicas quanto da ação concreta, do cotidiano dos homens e mulheres deste estudo, inclusive as condições da inserção na luta política para reivindicar direitos. Um dos aspectos que ocupa um grande espaço nas discussões e reivindicações dos/as idosos/as militantes diz respeito ao poder de compra de seus proventos de aposentadoria. As já referidas reformas da Previdência Social, iniciadas em 1995, têm resultado em profundas modificações na concessão e valores dos 
benefícios, implicando em grandes perdas para seus/as beneficiários/as e vêm encontrando acirrada oposição do movimento dos/as aposentados/as, pensionistas e idosos/as. Tais reformas no Brasil representam o cumprimento do ideário do estado mínimo neoliberal no que concerne às definições legais das três dimensões da política de proteção social - a Assistência Social, a Saúde e a Previdência Social - que estão sustentadas na perspectiva desse novo modelo de Estado. No que se refere a essa questão dos valores dos benefícios, homens e mulheres, tanto dos grupos de convivência quanto das associações de aposentados/as, são unânimes em apontar a incapacidade destes para atender a suas necessidades materiais básicas, condição elementar do direito do cidadão/ã.

Pago a água, pago a luz, pago as despesas do meu filho [26 anos e desempregado] que tá comigo; é pouco, mas o que é que se vai fazer? É pouco, não dá, se eu fosse sozinha não dava, quanto mais que eu tenho muita gente! (Nelma - 23/07/2007- CSU).

Olhe não é o ideal [...] tudo quem paga sou eu, a gente tem que saber administrar. [...] Agora mesmo eu estou precisando fazer um acabamento na minha casa e estou com dificuldades. Vou fazer uma pintura com tinta lavável que é mais barata [...] minha filha me pediu uma licença pra morar durante dois anos comigo [...] provavelmente, vai me ajudar... (Agnelo 03/12/2008 - Sesc).

Merece destacar ainda que, entre os/as idosos/as pesquisados/as, somente aqueles/as que participam da Associação de Aposentados/as e Pensionistas (Asaprev) revelam conhecimento sobre as razões das perdas e alimentam expectativas sobre as iniciativas que o movimento dos/as idosos/as vem travando nesse sentido.

0 beneficio só dá praticamente para o necessário e nem dá pra comprar remédio para minha patroa. Hoje temos uma perda de mais ou menos $80 \%$. Como é que se faz? Vamos ver se esse menino, o Paulo Paim [Senador] consegue reverter esse quadro ai, né? (Raimundo - 15/09/07 - Asaprev/BA).

Não é suficiente, porque foi retirado do meu benefício. Me aposentei com quase cinco salários mínimos e hoje estou com dois e poucos. Dois e meio salários mínimos me levaram, por isso que não dá, senão daria para viver tranquila. (Zônia-01/12/2008-Asaprev/Sesc).

Diante dessa grande defasagem - inclusive no tempo - dos valores dos benefícios dos/as idosos/as, pior ainda quando estes/as se tornaram arrimo de filhos maiores desempregados, a política que o governo Lula apresenta como pretensa solução é a 
aprovação da Lei $\mathrm{n}^{0} 10.953$, de 27 de setembro de 2004, publicada no DOU em 28/09/2004, que dispõe sobre os descontos que os beneficiários de aposentadoria e pensão do regime Geral da Previdência Social podem autorizar ao INSS para proceder em seus benefícios. Ainda dispõe sobre o direito desses beneficiários de autorizarem retenções, por parte das instituições financeiras nas quais recebam seus proventos, para fins de amortização de valores referentes ao pagamento mensal de empréstimos, financiamentos e operações de arrendamento mercantil por elas concedidos (CENTRAL DO CRÉDITO, 2006). Essa pretensa solução ofereceu um excelente filão de negócios para as instituições financeiras com garantia de perda zero e mais problemas no somatório de dificuldades dos idosos/as, que tiveram de lidar com novas dívidas para seus apertados orçamentos, conforme registrado nas falas dos entrevistados/as e em documentos divulgados pelas entidades articuladoras do movimento.

Tomei $\mathrm{R} \$ 1.000,00$, esse empréstimo piorou minha vida [...] aconselho a qualquer pessoa para não tomar esse dinheiro emprestado [...] a pessoa só toma porque está passando necessidade e acaba se apertando. Não é vantagem [...] esse empréstimo não beneficia ninguém... (Leandro 06/10/07).

Tomei $\mathrm{R} \$ 7.500,00$ para ajeitar minha vida. Não consegui fazer a reforma na casa, nem pagar o cartão de crédito e agora estou endividado. Dificultou minha vida. Você pega o dinheiro e depois vê que não tem condições de fazer o que precisava [...] me endividei de novo e ficou mais difícil pagar as contas. (Walmon - 27/10/2007)

A consciência da desvantagem é unânime, após ter passado a ilusão dos primeiros meses anteriores ao desconto, mas não alcança os que são beneficiários dessa política.

[...] foi a maior burrice da minha vida. Tomei empréstimo justamente pra comprar o terreno pra tentar fazer uma casa. Foi burrice, não deu certo. 0 terreno ta lá em Terra Nova. Comprei no interior por $\mathrm{R} \$ 2.000,00$ para pagar $\mathrm{R} \$ 10.000,00$, praticamente. Eu deveria ter pensado antes. Eu via aquelas propagandas e, como todo mundo, fui lá. Vi a propaganda e vi que tudo era maravilhoso na hora de tomar o empréstimo, aí eu disse: ah, meu Deus, é agora que eu vou ter a minha casa! Eu vi um horizonte maravilhoso! Peguei R\$ 2.000,00, comprei o terreno, não deu pra comprar os blocos, eu só adquiri o terreno. Não deu pra fazer a casa. Não deu pra fazer nada. Me atrapalhei toda. Atrapalhou a minha vida inteira. Agora tá muito mais difícil, porque todo mês desconta na folha e eu... mas agora eu prometo a 
mim mesma que eu vou passar longe... [risos]. (Anália - 02/12/2008 - Sesc /Asaprev/MSTS).

0 Fórum tem possibilitado ao movimento desenvolver muitas ações com vistas à implementação do Estatuto do Idoso, seguidas de reflexões sobre os direitos nele assegurados. Configura-se nessa práxis a possibilidade efetiva de transformação da consciência subalterna que caracteriza grande parte dos idosos, sobretudo as mulheres, para alcançar a condição de sujeito de seus atos, mediante o processo educativo da luta política.

As ações dos/as aposentados/as, pensionistas e idosos/as em movimento se revestem desse caráter pedagógico, na medida em que a situação real na qual os/as mais velhos/as vivem lhes serve de objeto de reflexão. Tais ações são assentadas na comunicação entre lideranças e a base do movimento, no diálogo entre subjetividades, mediado pela realidade marcada pela carência de poder que formata 0 cotidiano das pessoas de mais idade. Nesse processo, essas pessoas pouco a pouco se autodescobrem como despossuídas de poder; descoberta crítica de si, bem como das pessoas responsáveis por essa destituição e dos mecanismos utilizados nessa relação de opressão. Reside aí a estratégia do movimento para o convencimento, notadamente das/os idosas/os que compõem grupos de convivência, quanto à importância de assumirem a luta por sua emancipação, de modo a abandonarem as práticas para a submissão que povoa sua experiência de vida. Tal convencimento indica a necessidade de se autoconstituírem em sujeitos de suas próprias pautas de vida. Para tanto, devem apropriar-se de forma crítica da realidade que as destitui do poder de autodeterminação, para assim transformá-la, visto que, como reafirma Freire (1975), nenhuma realidade se transforma a si mesma.

No curso desse convencimento, no qual se instaura uma verdadeira ação pedagógica, os idosos, principalmente as mulheres, mas homens também, participantes de grupos de convivência se iniciam num novo processo educativo. Nessa dinâmica desenhada nos caminhos da ação política de reivindicação de direitos, promovida pelo Fórum, vão moldando sua conscientização.

Já tive, [em atividades políticas] quando foi prá ver se liberava o passe dos idosos de sessenta anos. A gente foi ali na Prefeitura. Tinha um bocado de grupo. (Tanira-23/07/07-CSU).

È muito importante [lutar pelos direitos]. Eu mesma já fui para a Câmara dizer que 60 anos não precisa pagar mais transporte, que a gente quer reivindicar isso. Mas ainda não veio a resposta. Temos lutado muito pela gratuidade aos 60 anos. (Elisângela - 02/12/08 - Sesc). 
Guardam, porém, significativa diferença, em comparação com homens e mulheres que participam da associação de aposentados/as e pensionistas. Seu nível de consciência da opressão que sofrem, do quão importante são as lutas políticas como possibilidade de melhores condições para as vidas das pessoas idosas, tanto do ponto de vista material quanto social e cultural, bem como suas motivações para participarem dessas ações, ainda estão numa fase de gestação. Em suas falas os/as idosos/as deixam transparecer suas diferenças quanto a essa questão:

Esse movimento tem ajudado muito. Nós já conseguimos o Estatuto do Idoso, a Delegacia do Idoso, que é uma coisa maravilhosa, a luta dos transportes gratuitos para o idoso, as assinaturas que conseguimos, tudo isso por aqui, porque a Bahia lidera em todas essas lutas; as propostas daqui são encaminhadas imediatamente. Esse Fórum Permanente, isso tudo foi iniciado aqui; por isso que são muito importantes essas atividades políticas, porque sem esses movimentos não se consegue nada, não, não se pode acomodar. (Gerônimo - 29/09/07 - Asaprev/BA).

Na época dos 147\%, eu fiz muito trabalho ali na Piedade; eu fiz uma peça que saiu no Jornal Nacional. Essa atividade política é muito importante Nós éramos decadentes, não tínhamos direito a nada. Os nossos direitos vêm daí, dessas lutas. Há grupos que viajam para Brasília para reivindicar perante os deputados, os senadores... (Zônia - 01/12/2008 - Asaprev-BA/Sesc/Sesi).

Algumas participam deste tipo de atividade de passeatas, mas eu não. Na minha concepção, essas passeatas só fazem é cansar a gente. Não resulta em nada, porque as autoridades competentes nunca dão valor a este tipo de passeata. Às vezes, eles até agridem. Hoje a gente não vê mais essa agressão, mas, antigamente, se agredia. (Aurino - 05/12/2008 - Sesc).

Todos esses depoimentos e muitos outros não transcritos, bem como as manifestações públicas e atividades diversas nas quais são atores, revelam que também as pessoas idosas alcançam a percepção da opressão, dominação e marginalização vivida pela condição de ser velho/a, isto é, processam tal situação no nível da consciência, à medida que se engajam na luta política destinada a sua superação. Vão, nesse processo, ampliando a visibilidade social dos/as idosos/as em suas lutas e fazendo-se reconhecidos/as como protagonistas de suas próprias demandas.

Sustento, neste estudo, a força e o alcance das estratégias desenvolvidas pelo movimento dos/as aposentados/as e pensionistas no âmbito de uma pedagogia para transformação da consciência dos/as idosos/as e reconheço quanto essa pedagogia tem significado perspectiva de poder para os mais velhos, destacando-se, nesse processo, as 
possibilidades de empoderamento das mulheres idosas. As mobilizações promovidas pelo Fórum, ancoradas nas definições do Estatuto do Idoso e no empenho de publicizar e fazer cumprir essa política, carregam, em sua dinâmica, esse potencial formador da consciência política, notadamente das mulheres idosas, quanto à subordinação tanto geracional quanto de gênero. Esse processo permitiu uma nova percepção sobre seus direitos e suas possibilidades: uma nova imagem de si, de sua condição de velho e de velha, informada por novos valores, vai-se formatando e impondo o reconhecimento de uma nova representação por toda a sociedade.

Armados com os instrumentos oferecidos por essa pedagogia, eles/as se assumem enquanto sujeitos políticos ativos que lutam para sustentar seus direitos e se mostram, uns mais outros menos, capazes de pautar suas vidas por suas próprias agendas. Questionam as tradicionais imagens da velhice e reivindicam-se dotados de todos os atributos para gozarem da confiança como cidadãos/ãs plenos/as. Assim, vão desenhando um novo caminho à medida que tomam consciência de seus direitos enquanto pessoas idosas que vivenciam o imbricamento de várias formas de discriminação. Nesse exercício de cidadania, no âmbito da organização coletiva e na mobilização de protesto, essas mulheres e homens que vivenciam a velhice vão construindo a própria percepção quanto às ideologias que subjazem às várias formas de opressão/dominação/exploração. Nesse percurso, vão adquirindo o potencial para se (re)afirmarem como sujeito social-político e se permitindo envelhecer com liberdade, à proporção em que vão demolindo essas barreiras estruturais da dominação geracional, de gênero, de classe social, de raça/etnia que historicamente os/as subjugam. Na condição de cidadãos/ãs idosos/as, vão assumindo, por direito, o poder nos espaços em que se tece a vida social.

A constituição do Fórum Permanente em Defesa do Idoso significa um esforço do movimento político dos/as idosos/as para gestar essa pedagogia que vem tensionando as estruturas que se fundam na prescrição de uma ordem impeditiva da plena liberdade daqueles/as que mais andaram no tempo, para decidir sobre seu modo de viver e agir. A referida pedagogia, que tomou por conteúdo a efetivação do que define o Estatuto do Idoso, realiza-se nas diversas atividades reivindicativas/formativas que despertaram novos interesses nas pessoas idosas que delas participam, especialmente as mulheres membros dos Grupos de Convivência de Idosas/os. Esses novos interesses, seguramente, vêm propiciando mudanças na consciência dessas pessoas no que diz respeito à ruptura do tradicional papel definido no âmbito das relações geracionais e de gênero. Assim, novos pertencimentos, com relação, inclusive, à participação política, vão sendo construídos e, por conseguinte, novos sujeitos emergem para a liberdade, vivenciando direitos enquanto cidadãos/ãs e ampliando a base do movimento dos aposentados/as, pensionistas e idosos em geral. Este/a continua como principal protagonista da defesa da 
aposentadoria, da Previdência Social Pública e de todos os direitos dos mais velhos/as; numa tensão permanente, vai impondo sua voz com autonomia.

0 grau de mobilização desses/as idosos/as tem influído na formulação e implementação de políticas voltadas para a população que envelhece e caracteriza sua insistência em participar das decisões que os afetam. É preciso destacar, porém, que como na maioria dos movimentos sociais na conjuntura pós-90, a expressividade pública do movimento dos aposentados refluiu, mas nunca abdicou de sua perspectiva transformadora. E os/as velhos/as em movimento insistem, tensionando pelo direito de continuarem na esfera pública, em intervir no processo que pensa a sociedade. Negam-se ao recolhimento à esfera privada de seus aposentos, abandonando suas agendas à vontade das gerações mais jovens.

Com a capacidade de luta que não se perde com o envelhecimento, permanecem desafiando, em muitas arenas do embate político, tudo aquilo que se apresenta como obstáculo a sua libertação das malhas da opressão/dominação geracional. Sob o impacto de nova pedagogia no âmbito das relações de poder que dão conteúdo aos conflitos entre as gerações, formata-se uma nova correlação de forças que vai definindo um novo lugar social para a velhice, de onde se fazem ouvir as gerações de velhos/as trabalhadores/as como interlocutoras dos interesses de todos/as os/as idosos/as.

\section{REFERÊNCIAS}

AZEVED0, Eulália Lima. Aposentados em movimento: tensões e convergências com 0 movimento sindical. 2005. Dissertação (Mestrado em Ciências Sociais) - Universidade Federal da Bahia, Salvador.

Um palco de múltiplas vozes: a nova invenção dos/as idosos/as em luta pela cidadania. 2010. Tese (Doutorado em Ciências Sociais) - Universidade Federal da Bahia, Salvador.

BRASIL. Constituição (1988). Texto constitucional de 5 de outubro de 1988, contendo as alterações adotadas pelas Emendas Constitucionais n $1 / 92$ a 30/2000 e pelas Emendas Constitucionais de Revisão nº 1 a 6/ 94. Brasília: Imprensa Nacional, Divisão de Editoração, 2000.

Presidência da República. Casa Civil. Subchefia para Assuntos Jurídicos. Lei $n^{\circ}$ 10.741/2003, de 3 de outubro de 2003. Dispõe sobre o Estatuto do Idoso e dá outras providências. Disponível em:

<http://www.planalto.gov.br/ccivil/LEIS/2003/L10.741.htm> . Acesso em: 19 set. 2007. 
BIRMAN, Joel. Futuro de todos nós: temporalidade, memória e terceira idade na psicanálise. In: VERAS, Renato (Org.). Terceira idade: um envelhecimento digno para 0 cidadão do futuro. Rio de Janeiro: Relume-Dumará/UnATI/UERJ, 1995. p. 29-48.

BOURDIEU, Pierre. Razões práticas: sobre a teoria da ação. Campinas: Papirus, 2003.

CABRAL, Benedita Edina da S. Lima. Recriar laços: estudo sobre idosos e grupos de convivência nas classes populares paraibanas. 2002. Tese (Doutorado em Ciências Sociais) - Universidade Estadual de Campinas, Campinas.

CENTRAL DO CRÉDITO. Home page. Disponível em: <www.centraldocredito.com>. Acesso em: 9 mar. 2006.

DEBERT, Guita Grin. A reinvenção da velhice: socialização e processos de reprivatização do envelhecimento. São Paulo: Ed. Fapesp, 1999.

FREIRE, Paulo. Pedagogia do oprimido. Rio de Janeiro: Paz e Terra, 1975.

HADAD, Eneida. A velhice de velhos trabalhadores: o cenário, o movimento e as políticas sociais. 1991. Tese (Doutorado em Sociologia) - Universidade de São Paulo, São Paulo.

HAREVEN, Tamara K. Novas imagens do envelhecimento e a construção do curso da vida. In: DEBERT, Guita (Org.). Gênero em gerações. Campinas: Cadernos Pagu, 1999. n. 13, p. 11-35.

MOTTA, Alda Britto da. Geração, a "diferença" do feminismo. In: SIMPÓSIO INTERNACIONAL - 0 DESAFIO DA DIFERENÇA. ARTICULANDO GÊNERO, RAÇA E CLASSE, 1., 2000, Salvador. Anais... Salvador: NEIM/UFBA, 2000.

SANTOS, Wanderley Guilherme dos. Cidadania e justiça: a política social na ordem brasileira. Rio de Janeiro: Campus, 1979.

SIMÕES, Júlio Assis. Solidariedade intergeracional e reforma da Previdência. Revista Estudos Feministas, Rio de Janeiro, v. 5, n. 1, 1997, p. 160-173.

Entre o lobby e as ruas: movimento de aposentados e politização da aposentadoria. 2000a. Tese (Doutorado em Ciências Sociais) - Universidade de Campinas, Campinas.

. A maior categoria do país: o aposentado como ator político. In: BARROS, Myriam M. Lins de (Org.). Velhice ou terceira idade? estudos antropológicos sobre identidade, memória e política. Rio de Janeiro: Fundação Getúlio Vargas, 2000b. p. $13-34$. 